Article

\title{
Treatment experience and predictive factors associated with re- sponse in platinum-resistant recurrent ovarian cancer: a retro- spective single-institution study
}

\author{
Radu Dragomir ${ }^{1}$, Ioan Sas ${ }^{2}$ *, Sorin Săftescu ${ }^{3}$, Dorel Popovici ${ }^{4}$, Roxana Margan ${ }^{5}$, Adelina Silvana Dragomir ${ }^{6}$, Horia \\ Stanca ${ }^{7}$, Valeria Mocanu ${ }^{8}$, Cristina Pac ${ }^{9}$ and Șerban Negru ${ }^{10}$
}

1 Department of Obstetrics and Gynecology, “Victor Babeș” University of Medicine and Pharmacy, 300041 Timisoara, Romania; dragomirradu91@gmail.com;

2 Department of Obstetrics and Gynecology, "Victor Babeș” University of Medicine and Pharmacy, 300041 Timisoara, Romania; sasioan56@yahoo.com;

3 Department of Oncology, “Victor Babeș" University of Medicine and Pharmacy, 300041 Timisoara, Romania; sorin251@yahoo.com;

4 Department of Oncology, “Victor Babeș” University of Medicine and Pharmacy, 300041 Timisoara, Romania; dorelpopovici@gmail.com

5 Doctoral school, "Victor Babeș” University of Medicine and Pharmacy, 300041 Timisoara, Romania; marganroxana@gmail.com;

6 Department of Oncology, “Carol Davila” University of Medicine and Pharmacy, 020021 Bucharest, Romania; adelina.silvana.gheorghe@gmail.com;

7 Department of Ophthalmology, "Carol Davila" University of Medicine and Pharmacy, 020021 Bucharest, Romania; hstanca@yahoo.com;

8 Department of Ophthalmology, "Victor Babes" University of Medicine and Pharmacy, 300041 Timisoara, Romania; valeria_mocanu@yahoo.com;

9 Department of Ophthalmology, "Victor Babes" University of Medicine and Pharmacy, 300041 Timisoara, Romania; kittysmileface@yahoo.com;

10 Department of Oncology, “Victor Babeș” University of Medicine and Pharmacy, 300041 Timisoara, Romania; snegru@yahoo.com;

* Correspondence: sasioan56@yahoo.com;

\begin{abstract}
Ovarian cancer (OC) represents the most common and lethal gynecologic malignancy, due to its increased incidence and mortality rate. It is usually diagnosed in advanced stages and, even though surgery and platinum-based treatment are initially efficient, recurrences emerge in over $70 \%$ of cases. Although there are multiple options of chemotherapy drugs from which to choose, little is known regarding the best strategy for prolonged survival. Thus, the aim of this study was to assess the effect that most frequently used chemotherapeutic regimens have upon time-to-treatment-failure (TTF) from the first line and beyond, considering clinical and biological factors which influence the treatment outcome of platinum-resistant recurrent OC. We retrospectively analyzed data from 78 patients diagnosed with platinum-resistant $\mathrm{OC}$, who underwent chemotherapy-based treatment with or without anti-angiogenic therapy at OncoHelp Oncology Center, Romania (January 2016 February 2021). Our study identified positive predictive factors for TTF related to anthropometry (age over 60 for patients treated with topotecan with or without bevacizumab), renal function (creatinine levels between 0.65 and $1 \mathrm{mg} / \mathrm{dl}$ for patients treated with regimens containing bevacizumab and pegylated liposomal doxorubicin) and treatment choice (bevacizumab in combination with pegylated liposomal doxorubicin or topotecan used from the first line and beyond).
\end{abstract}

Keywords: ovarian cancer; platinum resistance; prognostic factors

\section{Introduction}

Ovarian cancer (OC) remains one of the most common and deadly gynecological malignancies, with epidemiological discrepancies around the world. According to Globocan, 
in 2020, a number of 313,959 new cases of ovarian cancer were reported worldwide, with 207,252 deaths, thus showing an estimated mortality-incidence rate of $2 / 3$ [1]. OC presents 3 main histological types, with epithelial being the most frequent. This type, in turn, divides into 4 subtypes: serous (with its 2 forms: high-grade and low-grade), endometrioid, mucinous and clear-cell [2]. Not only that most ovarian cancer patients are diagnosed at an advanced stage [Féderation Internationale de Gynécologie et d'Obstétrique (FIGO) IIIIV], which leads to such a poor outcome, but over $70 \%$ present with a recurrence of the disease, despite response at initial treatment with surgery and platinum-based chemotherapy [3,4]. Novel targeted therapies, like anti-angiogenic drugs and Poly (ADP-ribose) polymerase (PARP) inhibitors were approved in the past decade, showing promising results regarding survival, when used as continuation maintenance (bevacizumab) or as switch maintenance (PARP inhibitors) $[5,6]$. However, relapses do occur and, the more often they manifest during a patient's lifetime, the shorter the progression-free survival (PFS) intervals between treatment regimens become [7].

Several subsequent chemotherapeutic regimens, although they are less standardized, are used to treat recurrent ovarian cancer (ROC), considering platinum-based treatment response. As such, patients with platinum-sensitive disease, who relapse after at least 6 months treatment-free interval, can still have a highly effective response to platinum-containing rechallenge (up to 60\%), showing a prolonged PFS and overall survival (OS) [811]. Moreover, associating targeted therapy as a maintenance treatment further prolongs PFS in the second-line setting [12]. Regarding the platinum-resistant subgroup, where relapse occurs in the first 6 months, response and survival rates are lower than the opposite when non-platinum therapies are used, a slightly better outcome being observed with the addition of targeted therapies than without them - PFS of 6.7 months for the addition of bevacizumab versus 3.4 months with chemotherapy alone [13]. Multiple chemotherapeutic drugs can be selected at physicians' choice in case of recurrences [e.g.: pegylated liposomal doxorubicin (PLD), topotecan, gemcitabine, paclitaxel], without significant discrepancies between them in terms of survival, but with different toxicity profiles [14, 15] and little information is known regarding the best selection of therapy and treatment algorithm to be used in the subsequent lines ( $>2$ nd line), for a prolonged survival and a better quality of life to be obtained [7, 16].

\section{Materials and Methods}

Study design

We developed a single institution-based observational retrospective cohort study on patients diagnosed with OC, treated at the OncoHelp Oncology Center, Timișoara, Romania, from January 2016 to February 2021. The aim of the present study was to assess the effect that most frequently used chemotherapeutic regimens have upon time-to-treatment-failure (TTF) from the first line and beyond, considering clinical and biological factors which influence the outcome of platinum-resistant ROC treatments in our center.

The inclusion criteria for the current study were: patients older than 18 years old, diagnosed with platinum-resistant OC (defined by recurrent disease within 6 months), confirmed by histopathological analysis, who underwent chemotherapy-based treatment with or without anti-angiogenic therapy. Patients with platinum-sensitive disease (defined by recurrent disease after more than 6 months following primary platinum-based treatment) at the beginning of the data collection were excluded.

Data collection

Clinical assessment, anthropometric and demographic data were collected from medical records, including age, performance status assessment by using Eastern Cooperative Oncology Group score (ECOG PS) and body-mass index (BMI). Hemogram (hemoglobin, neutrophil and lymphocyte count), biochemical parameters (creatinine), pathological diagnosis and initial tumor stage were also evaluated. 
We measured TTF in days, as the interval from initiation of chemotherapy to its premature discontinuation for any reason, including a decrease in ECOG PS, disease progression, treatment-related adverse events, end of documentation period, patient choice or death.

\section{Data analysis}

For the assessment of the data collected, we used Epi Info ${ }^{\mathrm{TM}}$ (version 7.2.2.6; trademark of the Centers for Disease Control and Prevention, Division of Health Informatics \& Surveillance, Center for Surveillance, Epidemiology \& Laboratory Services, Atlanta, GA) and MySQL Database Service ${ }^{\mathrm{TM}}$ (version 8.0; trademark of the Oracle Corporation). We used descriptive measures, such as percentages and corresponding $95 \%$ confidence intervals (CIs). We calculated the measures of central location (means) and dispersion [standard deviation (SD)] for the continuous numeric variables. The statistical analysis for the association of TTF with the demographic, anthropometric, clinical, hematological, biochemical and therapeutic variables was performed using the Cox Proportional Hazards Survival Regression (CPHSR), test available at https://statpages.info/prophaz.html. We computed the risk ratio (RR) and considered a P-value of 0.05 as the threshold for statistical significance.

\section{Results}

We identified 327 female patients treated at the OncoHelp Oncology Center for ovarian cancer, from January 2016 to February 2021, on which we applied the inclusion and exclusion criteria (Figure 1). A remaining total of $78(23.85 \%)$ patients were included in the current study, aged between 43 and 79, with a median age of 62 years old $(\mathrm{SD}=8.6)$.

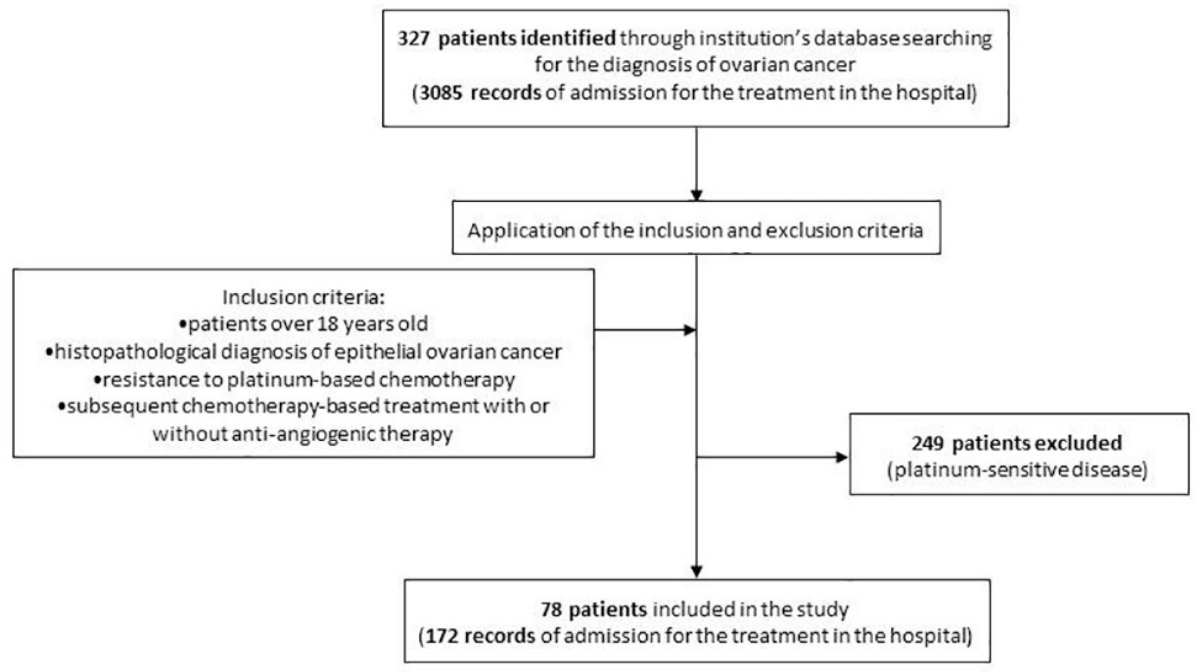

Figure 1. Study design flowchart and application of inclusion/exclusion criteria

The background and medical characteristics of the patients included in the study are summarized in Table 1. The most prevalent age group was between 60 and $69(43.59 \%$; 95\%CI: $32.39 \%-55.30 \%$ ), while most of the patients (52, 66.67\%; 95\%CI: $55.08 \%-76.94 \%$ ) had an ECOG PS equal to 1 at the beginning of the treatment. The distribution according to BMI was similar for normal-weight (25, 32.05\%; 95\%CI: $21.93 \%-43.58 \%)$, overweight (26, 33.33\%; 95\%CI: $23.06 \%-44.92 \%$ ) and obese patients (24, 30.77\%; 95\%CI: $20.81 \%-$ $42.24 \%$ ). 
Table 1. Background and medical characteristics of the patients undergoing first line of treatment: age, ECOG PS, BMI, subtype of EOC and initial disease FIGO stage

\begin{tabular}{|c|c|c|}
\hline Background characteristic & $\mathbf{n}$ & $\%$ (out of $N)[95 \% \mathrm{CI}]$ \\
\hline \multicolumn{3}{|l|}{ Age $(N=78)$} \\
\hline $40-49$ & 9 & $11.54 \%[5.41 \%-20.78 \%]$ \\
\hline $50-59$ & 22 & $28.21 \%[18.59 \%-39.53 \%]$ \\
\hline $60-69$ & 34 & $43.59 \%[32.39 \%-55.30 \%]$ \\
\hline Over 70 & 13 & $16.67 \%$ [9.18\%-26.81\%] \\
\hline \multicolumn{3}{|l|}{ ECOG PS $(\mathrm{N}=78)$} \\
\hline 0 & 19 & $24.36 \%[15.35 \%-35.40 \%]$ \\
\hline 1 & 52 & $66.67 \%$ [55.08\%-76.94\%] \\
\hline 2 & 7 & $8.97 \%[3.68 \%-17.62 \%]$ \\
\hline \multicolumn{3}{|l|}{ BMI (N = 78) } \\
\hline Below 18.5 (Underweight) & 3 & $3.85 \%[0.80 \%-10.83 \%]$ \\
\hline 18.5 - 24.9 (Normal weight) & 25 & $32.05 \%[21.93 \%-43.58 \%]$ \\
\hline 25.0 - 29.9 (Overweight) & 26 & $33.33 \%[23.06 \%-44.92 \%]$ \\
\hline Above 30.0 (Obesity) & 24 & $30.77 \%$ [20.81\%-42.24\%] \\
\hline \multicolumn{3}{|l|}{ Subtype of EOC $(N=62)$} \\
\hline Clear cell carcinoma & 3 & $3.85 \%[0.80 \%-10.83 \%]$ \\
\hline Endometrioid carcinoma & 2 & $2.56 \%[0.31 \%-8.96 \%]$ \\
\hline Serous carcinoma & 57 & $73.08 \%$ [61.84\%-82.50\%] \\
\hline Not specified & 16 & $20.51 \%[12.20 \%-31.16 \%]$ \\
\hline \multicolumn{3}{|l|}{ Initial disease stage $(\mathrm{N}=78)$} \\
\hline FIGO stage IA & 1 & $1.28 \%[0.03 \%-6.94 \%]$ \\
\hline FIGO stage IC & 3 & $3.85 \%[0.80 \%-10.83 \%]$ \\
\hline FIGO stage IIA & 2 & $2.56 \%[0.31 \%-8.96 \%]$ \\
\hline FIGO stage IIB & 1 & $1.28 \%[0.03 \%-6.94 \%]$ \\
\hline FIGO stage IIIA & 8 & $10.26 \%[4.53 \%-19.21 \%]$ \\
\hline FIGO stage IIIB & 6 & $7.96 \%[2.88 \%-15.99 \%]$ \\
\hline FIGO stage IIIC & 34 & $43.59 \%[32.39 \%-55.30 \%]$ \\
\hline FIGO stage IV & 23 & $29.49 \%$ [19.70\%-40.89\%] \\
\hline
\end{tabular}

EGOG PS = Eastern Cooperative Oncology Group score for Performance Status; BMI = body-mass index; EOC = epithelial ovarian cancer; FIGO = Féderation Internationale de Gynécologie et d'Obstétrique

All patients from the study had a histopathological diagnosis of epithelial ovarian cancer (EOC), serous carcinoma being the most frequent subtype identified (57, 73.08\%; 95\%CI: $61.84 \%-82.50 \%)$. Clear cell carcinoma and endometrioid carcinoma were present in low percentages (3.85\%; 95\%CI: $0.80 \%-10.83 \%$, respectively $2.56 \%$; $95 \% \mathrm{CI}: 0.31 \%-$ $8.96 \%)$, while for 16 patients $(20.51 \%)$ the subtype of EOC was not specified.

FIGO stage was assessed at the beginning of the treatment, when most of the patients were classified as FIGO stage IIIC (34, 43.59\%; 95\%CI: 32.39\%-55.30\%), followed by FIGO stage IV (23, 29.49\%; 95\%CI: 19.70\%-40.89\%). 
After the conversion to platinum-resistant disease, the patients underwent up to 9 treatment lines, in decreasing proportions: all of them received the first line of treatment, $51(65.38 \%)$ the second line, $25(32.05 \%)$ the third line, $11(14.10 \%)$ the fourth line, $3(3.84 \%)$ the fifth line and $1(1.28 \%)$ patient received also from sixth to the ninth line (Figure 2 ).

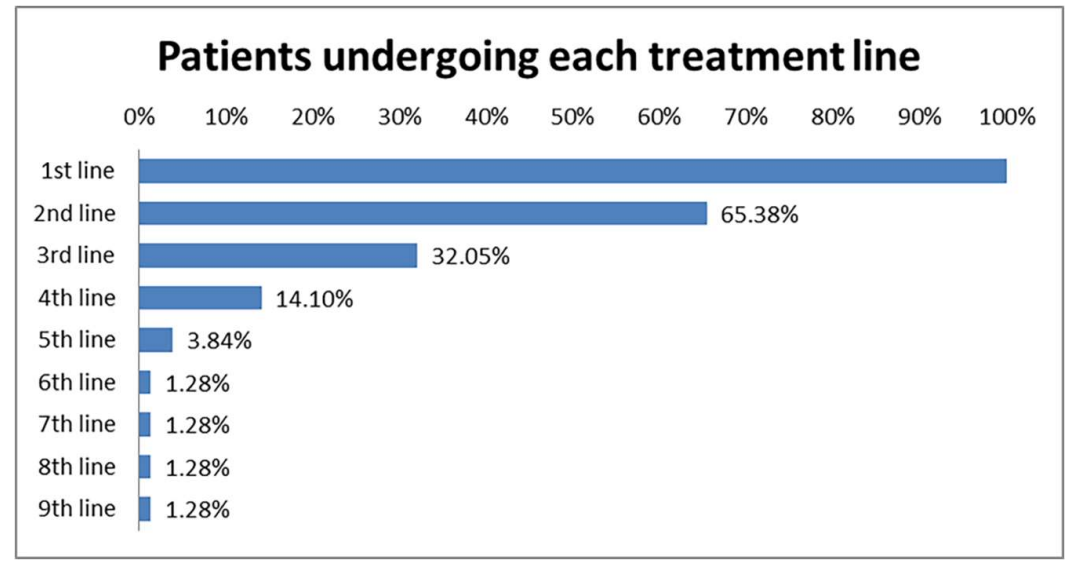

Figure 2. Percentages of patients undergoing each treatment line, after the conversion to platinumresistant disease

Treatment regimens included PLD, bevacizumab, carboplatin, etoposide, gemcitabine, paclitaxel, ifosfamide and topotecan, alone or in different combinations, as outlined in Table II and illustrated in Figure 3 (for lines 1-5). The only patient with 9 lines of treatment received carboplatin + paclitaxel in the 6th line, etoposide in the 7th, PLD in the 8 th and ifosfamide in the 9 th.

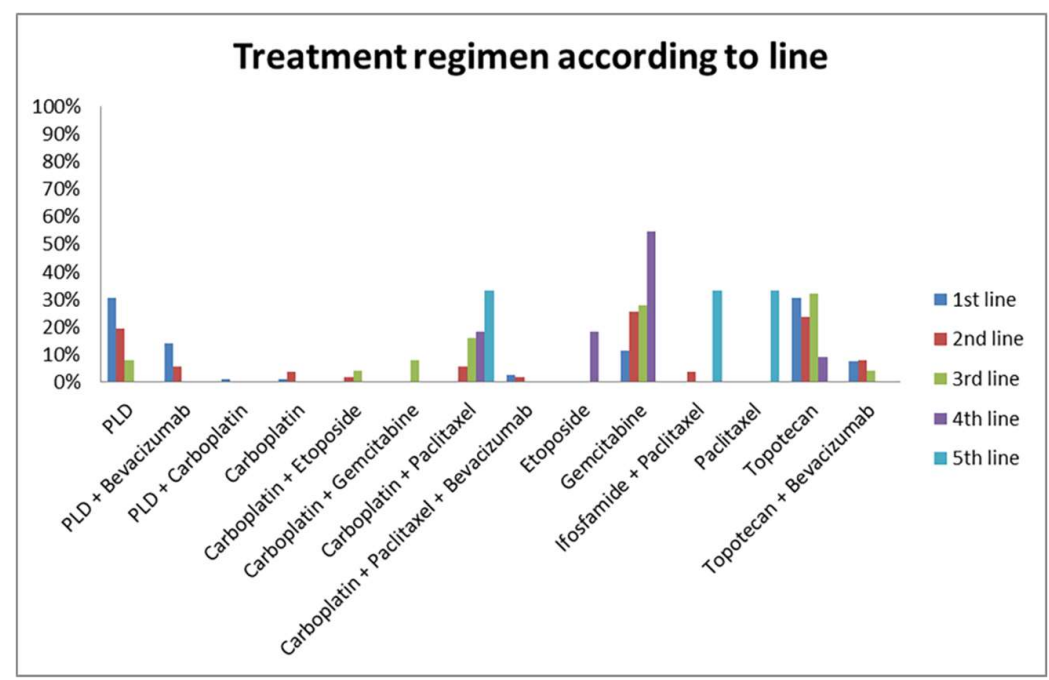

Figure 3. Percentage of patients for each treatment regimen (PLD, Bevacizumab, Carboplatin, Etoposide, Gemcitabine, Paclitaxel, Ifosfamide and Topotecan, alone or in different combinations) in lines 1 to 5 
Table 2. Number and percentage of patients for each treatment regimen (PLD, Bevacizumab, Carboplatin, Etoposide, Gemcitabine, Paclitaxel, Ifosfamide and Topotecan, alone or in different combinations) in lines 1 to 5

\begin{tabular}{|c|c|c|c|c|c|}
\hline \multirow{3}{*}{ Treatment regimen } & \multicolumn{5}{|c|}{ Line of treatment } \\
\hline & $1^{\text {st }}$ line & $2^{\text {nd }}$ line & $3^{\text {rd }}$ line & $4^{\text {th }}$ line & $5^{\text {th }}$ line \\
\hline & $(\mathrm{N}=78)$ & $(\mathrm{N}=51)$ & $(\mathrm{N}=25)$ & $(\mathrm{N}=\mathbf{1 1})$ & $(\mathrm{N}=3)$ \\
\hline PLD & $30.77 \%(24)$ & $19.61 \%(10)$ & $8.00 \%(2)$ & $0.00 \%(0)$ & $0.00 \%(0)$ \\
\hline PLD + Bevacizumab & $14.10 \%(11)$ & $5.88 \%(3)$ & $0.00 \%(0)$ & $0.00 \%(0)$ & $0.00 \%(0)$ \\
\hline PLD + Carboplatin & $1.28 \%(1)$ & $0.00 \%(0)$ & $0.00 \%(0)$ & $0.00 \%(0)$ & $0.00 \%(0)$ \\
\hline Carboplatin & $1.28 \%(1)$ & $3.92 \%(2)$ & $0.00 \%(0)$ & $0.00 \%(0)$ & $0.00 \%(0)$ \\
\hline $\begin{array}{l}\text { Carboplatin }+ \\
\text { Etoposide }\end{array}$ & $0.00 \%(0)$ & $1.96 \%(1)$ & $4.00 \%(1)$ & $0.00 \%(0)$ & $0.00 \%(0)$ \\
\hline $\begin{array}{l}\text { Carboplatin + } \\
\text { Gemcitabine }\end{array}$ & $0.00 \%(0)$ & $0.00 \%(0)$ & $8.00 \%(2)$ & $0.00 \%(0)$ & $0.00 \%(0)$ \\
\hline $\begin{array}{l}\text { Carboplatin + } \\
\text { Paclitaxel }\end{array}$ & $0.00 \%(0)$ & $5.88 \%(3)$ & $16.00 \%(4)$ & $18.18 \%(2)$ & $33.33 \%(1)$ \\
\hline $\begin{array}{l}\text { Carboplatin + } \\
\text { Paclitaxel + } \\
\text { Bevacizumab }\end{array}$ & $2.56 \%(2)$ & $1.96 \%(1)$ & $0.00 \%(0)$ & $0.00 \%(0)$ & $0.00 \%(0)$ \\
\hline Etoposide & $0.00 \%(0)$ & $0.00 \%(0)$ & $0.00 \%(0)$ & $18.18 \%(2)$ & $0.00 \%(0)$ \\
\hline Gemcitabine & $11.54 \%(9)$ & $25.49 \%(13)$ & $28.00 \%(7)$ & $54.55 \%(6)$ & $0.00 \%(0)$ \\
\hline Ifosfamide + Paclitaxel & $0.00 \%(0)$ & $3.92 \%(2)$ & $0.00 \%(0)$ & $0.00 \%(0)$ & $33.33 \%(1)$ \\
\hline Paclitaxel & $0.00 \%(0)$ & $0.00 \%(0)$ & $0.00 \%(0)$ & $0.00 \%(0)$ & $33.33 \%(1)$ \\
\hline Topotecan & $30.77 \%(24)$ & $23.53 \%(12)$ & $32.00 \%(8)$ & $9.09 \%(1)$ & $0.00 \%(0)$ \\
\hline $\begin{array}{l}\text { Topotecan + } \\
\text { Bevacizumab }\end{array}$ & $7.69 \%(6)$ & $7.84 \%(4)$ & $4.00 \%(1)$ & $0.00 \%(0)$ & $0.00 \%(0)$ \\
\hline
\end{tabular}

PLD = pegylated liposomal doxorubicin

Mean TTF was higher for obese patients (173.45 days) compared to overweight (mean TTF $=149.00$ days), normal weight (mean TTF $=146.48$ days) and underweight ones (mean TTF $=102.00$ days). Regarding the age group, the longest mean TTF (167.34 days) was observed for the patients between 60 and 69 years old, while the shortest mean TTF (121.12 days) for the group over 70 .

Table III shows the mean TTF for each treatment regimen and each line of treatment. Adding bevacizumab to the chemotherapy regimen (PLD, carboplatin + paclitaxel or topotecan) resulted in an increased mean TTF for all the lines in which it was administered (Table III). 
Table 3. Mean TTF (days) for each treatment regimen and each line of treatment

Line of treatment

\begin{tabular}{|c|c|c|c|c|c|c|c|c|c|}
\hline \multirow{2}{*}{ Treatment regimen } & \\
\hline & $1^{\text {st }}$ line & $2^{\text {nd }}$ line & $3^{\text {rd }}$ line & $4^{\text {th }}$ line & $5^{\text {th }}$ line & $6^{\text {th }}$ line & $7^{\text {th }}$ line & $8^{\text {th }}$ line & $9^{\text {th }}$ line \\
\hline PLD & 140.83 & 101.30 & 117.00 & - & - & - & - & 91.00 & - \\
\hline PLD + Bevacizumab & 195.54 & 393.66 & - & - & - & - & - & - & - \\
\hline PLD + Carboplatin & 474.00 & - & - & - & - & - & - & - & - \\
\hline Carboplatin & 148.00 & 254.50 & - & - & - & - & - & - & - \\
\hline $\begin{array}{l}\text { Carboplatin + } \\
\text { Etoposide }\end{array}$ & - & 21.00 & 98.00 & - & - & - & - & - & - \\
\hline $\begin{array}{l}\text { Carboplatin + } \\
\text { Gemcitabine }\end{array}$ & - & - & 204.50 & - & - & - & - & - & - \\
\hline $\begin{array}{l}\text { Carboplatin + } \\
\text { Paclitaxel }\end{array}$ & - & 206.33 & 139.75 & 222.50 & 359.00 & 116.00 & - & - & - \\
\hline $\begin{array}{l}\text { Carboplatin + } \\
\text { Paclitaxel + } \\
\text { Bevacizumab }\end{array}$ & 202.50 & 303.00 & - & - & - & - & - & - & - \\
\hline Etoposide & - & - & - & 144.50 & - & - & 91.00 & - & - \\
\hline Gemcitabine & 124.33 & 111.00 & 105.85 & 136.83 & - & - & & - & - \\
\hline Ifosfamide & - & - & - & - & - & - & - & - & 143.00 \\
\hline $\begin{array}{l}\text { Ifosfamide + } \\
\text { Paclitaxel }\end{array}$ & - & 103.50 & - & - & 260.00 & - & - & - & - \\
\hline Paclitaxel & - & - & - & - & 173.00 & - & - & - & - \\
\hline Topotecan & 121.29 & 117.08 & 133.62 & 52.00 & - & - & - & - & - \\
\hline $\begin{array}{l}\text { Topotecan }+ \\
\text { Bevacizumab }\end{array}$ & 236.16 & 409.50 & 150.00 & - & - & - & - & - & - \\
\hline
\end{tabular}

Serous ovarian carcinomas were significantly associated with a prolonged TTF than other histopathological diagnostics, when all treatment lines were taken into consideration $(\mathrm{RR}=0.7083, \mathrm{P}=0.0479)$.

Age and type of chemotherapy also seem to contribute to the total duration of treatment. Women under treatment with topotecan, older than 60 years of age, presented a prolonged TTF than the opposite age category $(\mathrm{RR}=0.5546, \mathrm{P}=0.0466)$, but not the same result was seen at women older than 60 years treated with gemcitabine, where age was associated with a higher risk of treatment failure than the younger category, although not statistically significant $(\mathrm{RR}=1.5735, \mathrm{P}=0.2154)$, while those under treatment with PLD did not show any significant difference $(R R=1.0882, P=0.77)$.

Analyzing several factors in relation to the total TTF in our cohort revealed that some of them could positively influence the outcome, but without statistical significance: BMI $(R R=0.0792, P=0.0792)$, creatinine level $(R R=0.2451, P=0.0553)$ and neutrophil count $(R R=$ $0.7913, \mathrm{P}=0.0515$ ) (Table 4). On the other hand, a biological factor that may raise concern in TTF was represented by baseline neutrophil values that exceed $6 \times 10^{\wedge} 9 / 1$, when taking into consideration all treatment regimens $(R R=2.2148, P=0.0645)$. In all treatment administrations that included bevacizumab, creatinine levels between 0.65 and $1 \mathrm{mg} / \mathrm{dl}$ further correlate with improved TTF $(R R=0.1182, P=0.0098)$. Better outcomes were also observed 
in PLD-based regimens used in patients who present with the same range for creatinine levels $(R R=0.2930, P=0.0170)$.

Table 4. Association of TTF with the demographic (age), anthropometric (BMI), clinical (ECOG PS), hematological $(\mathrm{Hb}, \mathrm{ANC}, \mathrm{ALC})$, biochemical $(\mathrm{Cr})$ and therapeutic variables (adding of antiangiogenic therapy - Bevacizumab), performed using the Cox Proportional Hazards Survival Regression

\begin{tabular}{lcc} 
& RR $(95 \% \mathrm{CI})$ & P-Value \\
\hline Age (years) (average 62.0178) & $1.0363(0.9926-1.0819)$ & 0.1047 \\
\hline BMI $\left(\mathrm{kg} / \mathrm{m}^{2}\right)$ (average 28.5132) & $0.9349(0.8673-1.0079)$ & 0.0792 \\
\hline ECOG PS (from 0 to 2) & $2.0042(0.5301-7.5765)$ & 0.3055 \\
\hline $\mathrm{Hb}(\mathrm{g} / \mathrm{dl})$ (average 11.225) & $0.7913(0.6252-1.0015)$ & 0.0515 \\
\hline ANC (x 10^9/l) (average 4.4875) & $1.0847(0.9364-1.2565)$ & 0.2785 \\
\hline ALC (x 10^9/1) (average 1.5771) & $0.8908(0.4425-1.7934)$ & 0.7461 \\
\hline $\mathrm{Cr}(\mathrm{mg} / \mathrm{dl})$ (average 0.9023) & $0.2451(0.0582-1.0327)$ & 0.0553 \\
\hline $\mathrm{ChT}+$ Bevacizumab (17/56) & $0.5782(0.2703-1.2365)$ & 0.1578 \\
BMI = body-mass index; EGOG PS = Eastern Cooperative Oncology $\mathrm{Group}$ score for Performance Status; Hb = hemoglobin level; \\
ANC = absolute neutrophil count; ALC = absolute lymphocyte count; Cr = creatinine level; ChT = chemotherapy
\end{tabular}

In cases where treatment regimens with topotecan and PLD included bevacizumab from the first line and beyond, statistically significant results were seen, as expected $(R R=$ $0.3332, \mathrm{P}=0.0087$ and $\mathrm{RR}=0.4187, \mathrm{P}=0.0228$, respectively). When comparing chemotherapy sequence between PLD in the first line, followed by topotecan and vice-versa, it seems like the tendency is to use PLD at the beginning ( $R R=0.7768, P=0.7096)$. Also, when bevacizumab is added in the regimens mentioned previously, the same tendency is observed $(\mathrm{RR}=0.1277, \mathrm{P}=0.0703)$. Moreover, age over 60 years old may be considered as a positive factor for TTF when treatment with PLD is used in the first line and beyond. Unfortunately, these results did not prove to be statistically significant.

\section{Discussion}

EOC represents approximately $90 \%$ of these malignant tumors and according to their morphology, there are several subtypes, such as: serous subtype, being the most frequent, $(68 \%-71 \%)$ followed by clear cell $(12 \%-13 \%)$, endometrioid $(9 \%-11 \%)$, mucinous $(3 \%)$, malignant Brenner (1\%) and mixed histology $(6 \%)$ subtypes [20, 21]. In a more recent classification, EOCs have been classified into five major subgroups based on histology, including high-grade serous carcinoma (HGSC; 70\%), low-grade serous carcinoma (LGSC; $<5 \%$ ), clear cell carcinoma (CCC; 10\%-15\%), endometrioid carcinoma (EC; 10\%), mucinous carcinoma (MC; $3 \%)$, that differ in tumor biology, pathogenesis, molecular alterations, risk factors, and prognosis [17, 22-24]. In our study, the incidence of serous subtype was the most frequent and significantly associated with a prolonged TTF compared with other histopathological diagnostics, when all treatment lines were taken into consideration ( $R R=$ 0.7083, $\mathrm{P}=0.0479$ ).

Even though TTF is an end point influenced by factors unrelated to efficacy, it reflects well the clinical applicability of targeted therapies in excessively pretreated patients, but is rarely used for regulatory drug approval [25, 26, 27].

Despite important progress that has been made in the treatment of OC, most patients with recurrent ovarian cancer will eventually develop platinum-resistant disease and receive second-line and sometimes several lines of treatment [28]. In general, platinum-resistant patients will be treated with sequential single agents rather than combination therapy, but the benefit of combined therapy and the incorporation of molecularly targeted therapies have significantly prolonged the median survival of patients [29]. However, 
combination chemotherapy may cause significant toxicity with a negative impact on patients' quality of life [30]. Moreover, the effect of combination chemotherapy on the quality of life of patients with recurrent ovarian cancer has not been sufficiently investigated in clinical trials [31]. It is well known that the benefit of any chemotherapy reduces with each successive line of treatment, as many patients are receiving more than one line of therapy for recurrent disease, usually platinum-based until platinum resistance emerges [28]. In our study, in cases where bevacizumab was added to PLD or topotecan regimens, significantly established bevacizumab as being positively associated with a good total TTF. This fact does not come as a surprise, since it is well known that in the AURELIA trial, consistently improved overall response rate and median PFS when used with topotecan (5.8 months vs 2.1 months, HR 0.32 95\% CI 0.21-0.49) and PLD (5.4 months vs 3.5 months, HR 0.57, 95\% CI 0.93-0.83) [32]. In addition, an interesting fact is that using PLD before topotecan could have been a better choice than vice-versa, including the cases where bevacizumab is added, although statistical significance is missing ( $R R=0.1277, P=0.0703)$. Regarding the influence of age on time to TTF when topotecan-based chemotherapy was used, good results were seen in elderly patients, confirming what Sorio et al described in the literature [33].

A study performed in 2020 on 283 patients with EOC who were divided into two groups: $<65$ years $(74.6 \%)$ group 1 and $\geq 65$ years, group $2(25.4 \%)$, showed that bevacizumab is not associated with an increase in G3/ G4 toxicity among the elderly, suggesting that age is not a predictive factor of adverse events for those receiving bevacizumab [34]. In our study, all treatment administrations that included bevacizumab, creatinine levels between 0.65 and $1 \mathrm{mg} / \mathrm{dl}$ further correlate with improved TTF ( $R R=0.1182, \mathrm{P}=0.0098)$.

The influence of body mass index on the risk and prognosis of ovarian cancer is subject to a lot of debate, as underweight or obese patients are considered to be a group of risk. In this group finding the right treatment seems to be more challenging, as chemotherapy-associated toxicity is one of the limiting factors regarding treatment response, patient outcome and quality of life [35-37]. In order to support this, a study published in 2018 aimed to evaluate the impact of BMI on the toxicity in patients undergoing chemotherapy. Their results showed BMI-associated differences in the number of administered cycles. The most important aspect was related to the fact that patients with lower BMI received fewer chemotherapy cycles in comparison to those with higher BMI [38]. Another study published in 2014 found that a lower BMI in patients with advanced-stage ovarian cancer is considered to be an early marker for poor prognosis and treatment discontinuation, as well accompanied by decreased immunity and advanced tumor inflammation [39]. A study published in 2015 suggested that body size should not be a major factor influencing dose reduction decisions in women with ovarian cancer [40]. Despite controversies regarding the influence of BMI on the risk and prognosis of high-grade serous ovarian cancer, there are very limited data available on BMI-related toxicities regarding systemic therapy [41-42]. In our study, although in the descriptive analysis we observed increased mean values of TTF being associated with increased BMI, statistical significance didn't prove in this situation.

Nevertheless, our study has its limitations: the number of patients included was relatively small, with disproportions due to the nature of a typical non-randomized study. Also, complete blood count and renal function test results were not available before December 2018, so analyses that included these assessments used fewer patients.

In conclusion, a few positive predictive factors were identified in our study: age over 60 years old for patients treated with topotecan with and without bevacizumab, creatinine levels between 0.65 and $1 \mathrm{mg} / \mathrm{dl}$ (for patients treated with PLD and regimens that contain bevacizumab) and the inclusion of bevacizumab in combination with PLD or topotecan as the physician's choice of treatment from the first line and beyond. 
Author Contributions: Conceptualization, R.D. and A.S.D.; methodology, R.D. and R.M.; validation, I.S., D.P. and S.N.; formal analysis, S.S. and H.S.; investigation, R.D. and R.M.; resources, S.N.; data curation S.S.; writing - original draft preparation, R.D., R.M. and A.S.D.; writing - review and editing, V.M. and C.P.; visualization, A.S.D.; supervision, I.S.; project administration, I.S. All authors have read and agreed to the published version of the manuscript.

Funding: This research received no external funding.

Institutional Review Board Statement: The study was conducted according to the guidelines of the Declaration of Helsinki and approved by the Ethics Committee of OncoHelp Oncology Center (11/04.03.2021).

Informed Consent Statement: Informed consent was obtained from all subjects involved in the study.

Conflicts of Interest: The authors declare no conflict of interest.

\section{References}

1. Sung H, Ferlay J, Siegel RL. Global Cancer Statistics 2020: GLOBOCAN estimates of incidence and mortality worldwide for 36 cancers in 185 countries. CA Cancer J Clin. 2021;0:1-41

2. Stewart C, Ralyea C, Lockwood S. Ovarian Cancer. An Integrated Review. Semin Oncol Nurs. 2019;35(2):151-156

3. Parmar MK, Ledermann JA, Colombo N, et al. ICON and AGO Collaborators. Paclitaxel plus platinum-based chemotherapy versus conventional platinum-based chemotherapy in women with relapsed ovarian cancer: the ICON4/AGO-OVAR2.2 trial. Lancet. 2003;361(9375):2099-106

4. International Collaborative Ovarian Neoplasm Group. Paclitaxel plus carboplatin versus standard chemotherapy with either single-agent carboplatin or cyclophosphamide, doxorubicin, and cisplatin in women with ovarian cancer: the ICON3 randomised trial. Lancet. 2002;360(9332):505-15

5. DiSilvestro P, Alvarez Secord A. Maintenance treatment of recurrent ovarian cancer: Is it ready for prime time? Cancer Treat Rev. 2018;69:53-65

6. Markman M. Maintenance chemotherapy in the management of epithelial ovarian cancer. Cancer Metastasis Rev. 2015;34(1):11-7

7. Hanker LC, Loibl S, Burchardi N, et al. AGO and GINECO study group. The impact of second to sixth line therapy on survival of relapsed ovarian cancer after primary taxane/platinum-based therapy. Ann Oncol. 2012;23(10):2605-2612

8. Fung-Kee-Fung M, Oliver T, Elit L, Oza A, Hirte HW, Bryson P, Gynecology Cancer Disease Site Group of Cancer Care Ontario's Program in Evidence-Based Care. Optimal chemotherapy treatment for women with recurrent ovarian cancer. Curr Oncol. 2007;14(5):195-208

9. Pfisterer J, Plante M, Vergote I, et al. AGO-OVAR; NCIC CTG; EORTC GCG. Gemcitabine plus carboplatin compared with carboplatin in patients with platinum-sensitive recurrent ovarian cancer: an intergroup trial of the AGO-OVAR, the NCIC CTG, and the EORTC GCG. J Clin Oncol. 2006;24(29):4699-707

10. Alberts DS, Liu PY, Wilczynski SP, et al. Southwest Oncology Group. Randomized trial of pegylated liposomal doxorubicin (PLD) plus carboplatin versus carboplatin in platinum-sensitive (PS) patients with recurrent epithelial ovarian or peritoneal carcinoma after failure of initial platinum-based chemotherapy (Southwest Oncology Group Protocol S0200). Gynecol Oncol. 2008;108(1):90-4

11. Pujade-Lauraine E, Wagner U, Aavall-Lundqvist E, et al. Pegylated liposomal Doxorubicin and Carboplatin compared with Paclitaxel and Carboplatin for patients with platinum-sensitive ovarian cancer in late relapse. J Clin Oncol. 2010;28(20):3323-9

12. Ray-Coquard I, Mirza MR, Pignata S, Walther A, Romero I, du Bois A. Therapeutic options following second-line platinumbased chemotherapy in patients with recurrent ovarian cancer: Comparison of active surveillance and maintenance treatment. Cancer Treat Rev. 2020;90:102107

13. Mancari R, Cutillo G, Bruno V, et al. Development of new medical treatment for epithelial ovarian cancer recurrence. Gland Surg. 2020;9(4):1149-63

14. Mutch DG, Orlando M, Goss T, et al. Randomized phase III trial of gemcitabine compared with pegylated liposomal doxorubicin in patients with platinum-resistant ovarian cancer. J Clin Oncol. 2007;25(19):2811-8

15. Gordon AN, Tonda M, Sun S, Rackoff W. Long-term survival advantage for women treated with pegylated liposomal doxorubicin compared with topotecan in a phase 3 randomized study of recurrent and refractory epithelial ovarian cancer. Gynecol Oncol. 2004;95(1):1-8

16. Bruchim I, Jarchowsky-Dolberg O, Fishman A. Advanced (>second) line chemotherapy in the treatment of patients with recurrent epithelial ovarian cancer. Eur J Obstet Gynecol Reprod Biol. 2013;166(1):94-8

17. Lheureux S, Braunstein M, Oza AM. Epithelial ovarian cancer: Evolution of management in the era of precision medicine. CA Cancer J Clin. 2019;69(4):280-304 
18. Vergote I, Denys H, De Greve J, et al. Treatment algorithm in patients with ovarian cancer. Facts Views Vis Obgyn. 2020;12(3):227-39

19. Lalwani N, Prasad SR, Vikram R, Shanbhogue AK, Huettner PC, Fasih N. Histologic, molecular, and cytogenetic features of ovarian cancers: implications for diagnosis and treatment. Radiographics. 2011;31(3):625-46

20. Hanby AM. Tavassoli FA, Devilee P. Pathology and Genetics: Tumours of the Breast and Female Genital Organs. WHO Classification of Tumours series-volume IV. Lyon, France: IARC Press. Breast Cancer Research. 2004;6(3):1-2

21. Rojas V, Hirshfield KM, Ganesan S, Rodriguez-Rodriguez L. Molecular Characterization of Epithelial Ovarian Cancer: Implications for Diagnosis and Treatment. Int J Mol Sci. 2016;17(12):2113

22. McCluggage WG. Morphological subtypes of ovarian carcinoma: a review with emphasis on new developments and pathogenesis. Pathology. 2011;43(5):420-32

23. Prat J. Ovarian carcinomas: five distinct diseases with different origins, genetic alterations, and clinicopathological features. Virchows Arch. 2012;460(3):237-49

24. Cancer Genome Atlas Research Network. Integrated genomic analyses of ovarian carcinoma. Nature. 2011;474(7353):609

25. Aust S, Schwameis R, Gagic T, et al. Precision Medicine Tumor Boards: Clinical Applicability of Personalized Treatment Concepts in Ovarian Cancer. Cancers (Basel). 2020;12(3):548

26. Wheler JJ, Janku F, Naing A, et al. Cancer therapy directed by comprehensive genomic profiling: a single center study. Cancer Res. 2016;76(13):3690-701

27. Pazdur R. Endpoints for assessing drug activity in clinical trials. Oncologist. 2008;13(Suppl 2):19-21

28. Luvero D, Milani A, Ledermann JA. Treatment options in recurrent ovarian cancer: latest evidence and clinical potential. Ther Adv Med Oncol. 2014;6(5):229-39

29. Pujade-Lauraine E, Combe P. Recurrent ovarian cancer. Ann Oncol. 2016;27:i63-5

30. Chase DM, Wenzel L. Health-related quality of life in ovarian cancer patients and its impact on clinical management. Expert Rev Pharmacoecon Outcomes Res. 2011;11(4):421-31

31. Bouberhan S, Pujade-Lauraine E, Cannistra SA. Advances in the management of platinum-sensitive relapsed ovarian cancer. J Clinical Oncol. 2019;37(27):2424-36

32. Pujade-Lauraine E, Hilpert F, Weber B, et al. Bevacizumab combined with chemotherapy for platinum-resistant recurrent ovarian cancer: the AURELIA open-label randomized phase III trial. J Clin Oncol. 2014;32(13):1302-8

33. Sorio R, Roemer-Becuwe C, Hilpert F, et al. Safety and efficacy of single-agent bevacizumab-containing therapy in elderly patients with platinum-resistant recurrent ovarian cancer: Subgroup analysis of the randomised phase III AURELIA trial. Gynecol Oncol. 2017;144(1):65-71

34. Amadio G, Marchetti C, Villani ER, et al. ToleRability of BevacizUmab in elderly Ovarian cancer patients (TURBO study): a case-control study of a real-life experience. J Gynecol Oncol. 2020;31(1):e6

35. Torre LA, Bray F, Siegel RL, Ferlay J, Lortet-Tieulent J, Jemal A. Global cancer statistics, 2012. CA Cancer J Clin. 2015;65(2):87-108

36. Dixon SC, Nagle CM, Thrift AP, Pharoah PD, Pearce CL, Zheng W, Painter JN, AOCS Group \& Australian Cancer Study (Ovarian Cancer), Chenevix-Trench G, Fasching PA, Beckmann MW. Adult body mass index and risk of ovarian cancer by subtype: a Mendelian randomization study. Int J Epidemiol. 2016;45(3):884-95

37. Pergialiotis V, Doumouchtsis SK, Perrea D, Vlachos GD. The impact of underweight status on the prognosis of ovarian cancer patients: A meta-analysis. Nutr Cancer. 2016;68(6):918-25

38. Grabowski JP, Richter R, Rittmeister H, Chekerov R, Woopen H, Sehouli J. Impact of body mass index (BMI) on chemotherapy-associated toxicity in ovarian Cancer patients. a pooled analysis of the north-eastern german society of gynecological oncology (NOGGO) databank on 1,213 patients. Anticancer Res. 2018;38(10):5853-8

39. Kim SI, Kim HS, Kim TH, et al. Impact of underweight after treatment on prognosis of advanced-stage ovarian cancer. J Immunol Res. 2014;2014:349546

40. Bandera EV, Lee VS, Rodriguez-Rodriguez L, Powell CB, Kushi LH. Impact of chemotherapy dosing on ovarian cancer survival according to body mass index. JAMA oncology. 2015;1(6):737-45

41. Gutierrez F, Gonzalez-de-la-Fuente GA, Nazco GJ, Oramas J, Batista N. Hematological toxicity of carboplatin for gynecological cancer according to body mass index. Eur J Clin Pharmacol. 2016;72(9):1083-9

42. Au-Yeung G, Webb PM, DeFazio A, Fereday S, Bressel M, Mileshkin L. Impact of obesity on chemotherapy dosing for women with advanced stage serous ovarian cancer in the Australian ovarian cancer study (AOCS). Gynecol Oncol. 2014;133(1):16-22 